\title{
What Alternative and Innovative Sources of Healthcare Finance Can Be Explored for the Sustainability of the National Health Insurance Scheme of Ghana? Perspectives of Health Managers
}

Alexander Suuk Laar ( $\sim$ laar.alex.suuk@gmail.com )

REJ Institute https://orcid.org/0000-0002-0721-4533

Michael Asare

Holy Family Hospital, Koforidua

Philip Ayizem Dalinjong

Navrongo Health Research Centre, Ghana

\section{Research}

Keywords: Universal Health Coverage, National Health Insurance Scheme, alternative local funding, Health managers, healthcare financing challenges, sustainability, Ghana

Posted Date: September 21st, 2020

DOl: https://doi.org/10.21203/rs.3.rs-67642/v1

License: (c) (i) This work is licensed under a Creative Commons Attribution 4.0 International License. Read Full License 


\section{Abstract}

Background Sustainable healthcare financing is one of the key components for the achievement of universal health coverage (UHC) globally. This study explored health managers views on alternative and sustainable healthcare financing sources for the National Health Insurance Scheme (NHIS) in Ghana.

Methods A qualitative study using in-depth interviews with 16 health facility managers were held. The participants were selected using purposive sampling. A written consent was obtained from participants prior to participation in the interview. Data was transcribed verbatim and analyzed using thematic framework approach.

Results All the participants indicated reimbursement of claims to health facilities by the NHIS as the main challenge. They attributed reasons to inadequate provision of funds from Government and the National Health Insurance Authority. Concerns were raised about how the situation affected health managers' delivery of services to insured clients. Participants suggested exploring of additional funding sources by levying of special taxes on incomes from local natural resources and telecommunication service companies in Ghana to raise additional funds.

Conclusion The findings of this study are important to government of Ghana and similar settings in LMICs who are working towards sustainable financing of their UHC system.

\section{Background}

Sustainable healthcare financing is one of the key components for the achievement of universal health coverage (UHC) [1]. UHC is defined as providing financial protection from the costs of using health services for all people of a country, as well as enabling them to obtain the health services that they need, where these services should be of sufficient quality to be effective [2]. Emphasis has been placed on how to finance health systems to move towards UHC [3-5]. Financing UHC is complex and difficult in Low and Middle Income Countries (LMICs) especially where the informal sector dominates [6, 7]. Health care financing continues to generate heated discussion in LMICs, especially how this could be sustainably carried out [8]. Health policy makers and other stakeholders are particularly challenged in this direction[8, 9]. Universal access to healthcare and sustainable financing are important health system goals [10],since sound financing strategies tend to impact on access to health services and health outcomes [11]. However, adequate and sustainable financing of the public health system continues to evade most LMICs, in which health systems struggle with scant and inequitably distributed resources [11].

As part of renewed efforts at pursuing sustainable health care financing options that promote UHC, Ghana has adopted a National Health Insurance Scheme (NHIS) to provide universal access to health care for all at an affordable cost [12-16]. The sources of the Scheme's funds come from members registration fees and an indirect tax(Value Added Tax levy of 2.5\%), which contributes over seventy percent of healthcare financing in Ghana $[13,14]$. Since the NHIS inception over one and half decades ago, Ghana has made substantial progress in terms of coverage and improved health service utilization 
and health outcomes $[12,14,17]$. Notwithstanding the positive outcomes, there have been financial challenges in terms of reimbursement of claims to healthcare facilities [14].

Claims reimbursement to health facilities continue to be a challenge affecting quality healthcare provision $[12,13]$. This has been a matter of concern and continue to draw the attention of researchers and stakeholders of the NHIS as well as the health system $[12,13]$. It is a major topic of debate by all stakeholders. While challenges with regards to quality of healthcare service has been explored from different perspectives within the Ghanaian context [12,17-20], there is limited knowledge on sustainable funding sources for healthcare financing in Ghana. Financial sustainability of NHIS in the context of Ghana refers to the scheme being able to operate overcoming financial encumbrances due to limited funds for provider reimbursement and other administrative activities. To fill this research gap, our research explored the views of health managers and insurance officers on sustainable sources of domestic funding for healthcare in Ghana.

\section{Methods}

\section{Study setting}

The study was undertaken in four district hospitals (Holy family hospital, Kwahu government hospital, Atua government hospital and St. Martins De Porres hospital) in the Eastern Region of Ghana. They comprised of public/government and mission or Christian Council Association of Ghana hospitals.

\section{Data management}

\section{Data collection and participants}

A qualitative study using in-depth interviews with 16 health facility managers from four health facilities. The participants comprised of medical directors, insurance claims officers, hospital administrators and accountants.

The study participants were purposively selected using convenient sampling. The health facilities were also purposively selected. In-depth interview guide with semi-structured questionnaire were used. Participants were assured of anonymity and confidentiality of the information that will be collected from them. A written consent was obtained from participants prior to participation in the interview. The interviews were tape-recorded with the permission of participants which lasted between 45 and 60 minutes.

\section{Data analysis}

The recorded interviews were transcribed verbatim and analysed thematically using Clarke and Braun's framework [21].Transcribed interviews were first read through word by word and codes were derived from the participants' statements. Similar codes were grouped together into one theme or broader themes 
which were reviewed severally by the researchers. For coherency, preliminary themes within a theme were developed to aid interpretation and extracts to support narratives and analysis.

\section{Results}

\section{Views on health managers on claims reimbursement to health facilities}

Health managers' views were sought on claims' reimbursement and its effects on healthcare provision in the health facilities. Almost all the managers interviewed in the four facilities were not satisfied with how claims were reimbursed. That submitted claims took a long time to be paid by NHIA. Apart from the irregularity of the imbursement, it does not often cover the total amount owed/submitted. Some of their views are expressed in the following statements:

the claims reimbursement from the NHIA has been erratic. The authority does not pay according to the plan of four weeks as stated in the Act......... Reimbursement from the authority takes several months to come to hit our account. The more worrying thing is that whenever

payment is made, it does not cover all the months owed us. For now, they owe our facility over eight to ten months but if they are paying, it will cover only two or three months which is not the best for hospital management...... if you go to all the regions, they will tell you the same story.... it is really affecting us in several ways......there is need for lasting solution to this problem" [Hospital Administrator].

the claims payments to health facilities continue to become worst as days go by....... as it is not regular, the payments also come in bits as part payments sometimes covering few months out of the lot owed to the facility. It's really affecting the operations of health facilities it is a general issue for the facilities in the country. It's really affecting our ability to manage our facilities......." (Hospital Accountant)

\section{Effects of delayed reimbursement on healthcare delivery to clients}

Healthcare managers acknowledged that the erratic nature of reimbursement affected their ability to provide standard healthcare as expected by their clients. A medical director expressed his opinion on the delayed claims reimbursement.

“...... the financial challenges are affecting our ability to provide the care required by our clients. ... our situation now is like a boxer whose hands are been tied behind him and expected to fight his opponent in the ring and win the fight............ which is impossible. So, our situation is the same thing.... how can we provide quality or standard healthcare to our client with resources.......? This is not possible We try to do our best though. " (Medical director).

The participants also reported that the lack of claims reimbursement affected adequate provision of healthcare to insured clients. A manager said: 
"The financial challenge we are facing is also affecting our clients seriously...... they do not get the standard of quality services required from us. Sometimes we tell them to pay for some of the from their pocket or make co-payments that is when there are in stock. If the drugs are not in stock, we tell them or purchase them from outside the facility. They are always not happy when they hear this .... But there is nothing one can do. so that is the current situation. It's really affecting all of us" (Medical director).

Concerning the same issue, views of the health insurance officers were not different. An insurance officer indicated:

"If the poor which the insurance was meant to protect are now made to pay for healthcare services then it is no more serving the purpose..........then this is the time for the insurance managers and the government to rethink on how to overcome these financial threats" (Claims manager).

\section{Health managers views on reasons for delayed claims reimbursement.}

We explored health managers views on reasons accounting for the delay in reimbursement of claims to the health facilities. This is a statement from one of the managers:

The delay in payment is due to the inability of the NHIA to provide enough funds for payment as a result of government's failure to advance funds to the NHIA (Hospital administrator).

The managers also attributed the delay to politics and management issues as reflected in the following statements:

"There is meddling of politics in the management of the scheme's affairs too much.... it is not the best for sustainability for the NHIS (Hospital administrator).

\section{Views on how to address financial challenges for claims reimbursement}

We sought participants views on how the current financial challenges of the NHIA can be tackled. Some participants believe that the only way to overcome the current financial challenges faced by the NHIA is to explore alternative and sustainable sources of funding by the government through the levying of special taxes on our natural resources and existing tax sources. A manager suggested:

"It is possible for the government to impose some levies from the proceeds from our natural resources such as gold, cocoa, bauxite and oil and gas to support health care in the country. If all these potential sources are available and the government is facing challenges of raising funds to finance healthcare.... it is very difficult to comprehend. The government need to explore these sources t urgently since the HHIS is in financial crisis" (Medical director).

"I think raising the proportion of the current VAT to finance healthcare will be a bad thing at all...... that source has been supportive to the government and also reliable though....." (Hospital accountant). 
Other participants have the view that the government could raise additional funds by taxing telecommunication sector services. A participant said:

"...... the government can raise additional funds locally by imposing special taxes on mobile money transfers to augment healthcare funds...." (Insurance claims officer).

Other participants also think that funds could be raised from taxes on airtime. A hospital administrator indicated:

"By the government by introducing airtime tax to raise revenue to finance healthcare as done in some countries. We can also do that in Ghana. This is easy and reliable way for the government to raise more funds to support healthcare provision in the country"

Participants think that while putting financial policies in place, pragmatic financial measures also need to be put in place to ensure judicious use of the funds for their intended purposes. A participant reported:

"............. any official or individual who misapply the scheme's funds should be fined and prosecuted to serve as a deterrent to others or else........ if we fail to do that .... we can continue to put in more funds but the financial challenges will persist" (Hospital accountant)

\section{Discussion}

Our findings indicate a long-standing claims debt of several months owed to the healthcare facilities by the NHIA. Delayed claims reimbursement of service providers remains a key concern by NHIS-accredited health facilities in Ghana [12-14, 19,22]. This has compelled them to sometimes demand out-of-pocket or co-payments from clients to be able to deliver services needed to them. Health managers expressed frustration in delayed reimbursement of claims by the NHIS. Delayed reimbursement coupled with poor quality of service remain critical challenges that have the potential of reversing to out-of-pock payment system in Ghana. It could also lead to decreased stakeholders' trust and confidence [12, 14, 22, 23]. Health managers think there is the need for the NHIA and Government of Ghana to find immediate and sustainable financial solution to thecurrent crisis to ensure timeous release of payments. According to WHO[24], to achieve sustainable quality health services, health systems should be capable of raising adequate funds for equitable health service provision without exposure to undue financial hardship [25]. However, ensuring adequate funding for healthcare by governments especially in LMICs like Ghana has been a herculean task over the years [26].

Proposals for additional and sustainable sources of revenue for the NHIS was discussed to address this perennial encumbrance. Participants discussed the need for the government of Ghana to consider the imposition of special levies on mobile communication and money transfers to raise additional funds to finance healthcare. Gabon [27] was able cover her population who were not economically capable of contributing to the National Health Insurance scheme, by levying a specific tax on the mobile phone 
services to raise funds [27]. Mobile phones levies are becoming one of the world's major source of health funding which other LMICs like Ghana could explore.

To broaden the funding sources for the healthcare sector, will require special taxes on Ghana's natural resources such as oil and gas, gold, cocoa, bauxite to support the healthcare budget. According to International Monetary Fund (IMF), the discovery of natural resources such as above in Ghana and other LMICs could offer opportunities for increasing economic growth and tax revenues [26] to support health and other sectors of their economies. Papua New Guinea is a classic example of a country in a LMIC category that has implemented a series of tax policies during the last two decades, using proceeds from the country's copper and gold mine to fund health [26] that Ghana and other countries might consider.

It was also proposed for the increasement of the proportion of the Value Added Tax levy. Currently in Ghana, the Value Added Tax levy of $2.5 \%$ contribute over seventy percent of the National Health Insurance Scheme's funds for healthcare provision in Ghana $[28,29]$.The importance of raising revenue through tax levies in LMICs to finance healthcare services at various stages of UHC is highlighted in studies in Costa Rica, Malawi, Indonesia and Thailand [26, 28]. However, policy makers are cautioned to find ways to minimize the regressive impact of indirect taxes to make them a feasible source of revenue in a non-contributory health financing system[6].

Health managers suggested the need to de-couple the management of the NHIS from political interference and also to prosecute those who mismanage funds. To achieve this, participants suggested putting in place adequate monitoring measures across the health system [7]. They think failure by the government and the NHIA to institute appropriate monitoring measures over time could stifle financial sustainability efforts. Similar studies in Ghana have come out with similar recommendations $[13,30]$. Detailing this finding is not possible within the scope of this document since it was not the focus. Evidence shows that the amount of money is only one determinant of the ability to improve population health and well-being[26] but variations in the efficiency with which the available funds are used is one of the reasons why some countries obtain better health outcomes for the resources they invest than do others [26].

\section{Study Limitations}

This study has some limitations which should be noted. The study setting involved four healthcare facility managers in one region in Ghana, and the recommendations did not capture the general views of all healthcare facility managers in Ghana. However, these categories of managers are senior public health administrators and their ideas or views will not differ significantly from the rest of the other healthcare facility managers in Ghana. As the first study to capture healthcare managers views on potential sustainable domestic sources of funding in Ghana, the instrument may be refined to capture the views of other stakeholders from the health sector.

\section{Conclusions}


The study provides important insights on sustainable domestic funding sources for financing UHC in Ghana and similar settings in LMICs. What is required is the need for the establishment of the necessary legal and policy frameworks to support the recommendations. Also, averting this financial challenge will largely depend on concerted efforts of key stakeholders such as health insurance managers, service providers, policy makers and political actors. The findings are important to governments and health policy makers in Ghana and in LMICs who are working towards sustainable financing of their healthcare system.

\section{Declarations}

\section{Ethical considerations}

The study obtained institutional approval from Holy Family Hospital. Permission for the research was also obtained from the management of individual hospitals. A written informed consent was obtained from all participants before participating in the study.

\section{Availability of data and materials}

The datasets used and/or analysed during the current study are available from the corresponding author on request.

\section{Competing interests}

The authors declare that they have no competing interests.

\section{Consent for publication}

Not Applicable.

\section{Acknowledgements}

The study team gratefully acknowledges the health managers whose support and participation made this study possible.

\section{Funding}

No funding was received for this study.

\section{Authors' contribution}

ASL conceived and designed the study, MA collected the data., MA transcribed the data, ASL analysed the data, ASL prepared the manuscript, MA and PAD revised the manuscript, PAD provided critical intellectual inputs. All authors read and approved the final manuscript. 


\section{References}

1. World Health Organization, Universal health coverage: moving towards better health: action framework for the Western Pacific Region. 2016, Manila: WHO Regional Office for the Western Pacific.

2. World Health Organization, The world health report: health systems financing: the path to universal coverage: executive summary. 2010, World Health Organization.

3. Stenberg, K., et al., Financing transformative health systems towards achievement of the health Sustainable Development Goals: a model for projected resource needs in 67 low-income and middleincome countries. The Lancet Global Health, 2017. 5(9): p. e875-e887.

4. Stenberg, K., et al., Responding to the challenge of resource mobilization-mechanisms for raising additional domestic resources for health. World health report, 2010.

5. Kutzin, J., Health financing for universal coverage and health system performance: concepts and implications for policy. Bulletin of the World Health Organization, 2013. 91: p. 602-611.

6. Okungu, V.R. and D. Mclntyre, Does the informal sector in Kenya have financial potential to sustainably prepay for health care? Implications for financing universal health coverage in lowincome settings. Health Systems \& Reform, 2019. 5(2): p. 145-157.

7. Kutzin, J., W. Yip, and C. Cashin, Alternative financing strategies for universal health coverage, in World Scientific Handbook of Global Health Economics and Public Policy: Volume 1: The Economics of Health and Health Systems. 2016, World Scientific. p. 267-309.

8. Schieber, G., et al., Financing health systems in the 21 st century. Disease control priorities in developing countries, 2006. 225: p. 224.

9. World Health Organization, World report on health policy and systems research. 2017.

10. Wiysonge, C.S., et al., Financial arrangements for health systems in low-income countries: an overview of systematic reviews. Cochrane Database of Systematic Reviews, 2017(9).

11. Palmer, N., et al., Health financing to promote access in low income settings-how much do we know? The Lancet, 2004. 364(9442): p. 1365-1370.

12. Dalinjong, P.A. and A.S. Laar, The national health insurance scheme: perceptions and experiences of health care providers and clients in two districts of Ghana. Health economics review, 2012. 2(1): p. 13.

13. Alhassan, R.K., E. Nketiah-Amponsah, and D.K. Arhinful, A review of the National Health Insurance Scheme in Ghana: what are the sustainability threats and prospects? PloS one, 2016. 11(11).

14. Owusu-Sekyere, E. and D.A. Bagah, Towards a sustainable health care financing in Ghana: Is the National Health Insurance the solution? 2014.

15. Blanchet, N.J., G. Fink, and I. Osei-Akoto, The effect of Ghana's National Health Insurance Scheme on health care utilisation. Ghana medical journal, 2012. 46(2): p. 76-84.

16. Dzakpasu, S., et al., Impact of free delivery care on health facility delivery and insurance coverage in Ghana's Brong Ahafo Region. PloS one, 2012. 7(11). 
17. Atinga, R.A., Healthcare Quality under the national health insurance scheme in Ghana. International Journal of Quality \& Reliability Management, 2012.

18. Atinga, R.A. and A.A. Baku, Determinants of antenatal care quality in Ghana. International Journal of Social Economics, 2013.

19. Sakyi, E.K., R.A. Atinga, and F.A. Adzei, Managerial problems of hospitals under Ghana's national health insurance scheme. Clinical Governance: An International Journal, 2012.

20. Turkson, P., Perceived quality of healthcare delivery in a rural district of Ghana. Ghana medical journal, 2009. 43(2).

21. Clarke, V., V. Braun, and N. Hayfield, Thematic analysis. Qualitative psychology: A practical guide to research methods, 2015: p. 222-248.

22. Macha, J., et al., Factors influencing the burden of health care financing and the distribution of health care benefits in Ghana, Tanzania and South Africa. Health policy and planning, 2012. 27(suppl_1): p. i46-i54.

23. Alhassan, R.K., et al., Perspectives of frontline health workers on Ghana's National Health Insurance Scheme before and after community engagement interventions. BMC health services research, 2016. 16(1): p. 192.

24. Organization, W.H., Everybody's business--strengthening health systems to improve health outcomes: WHO's framework for action. 2007.

25. Agyepong, I.A., et al., Advancing the application of systems thinking in health: provider payment and service supply behaviour and incentives in the Ghana National Health Insurance Scheme-a systems approach. Health Research Policy and Systems, 2014. 12(1): p. 35.

26. Elovainio, R. and D.B. Evans, Raising and spending domestic money for health. 2013: Chatham House.

27. Musango, L. and I. Aboubacar, Assurance Maladie Obligatoire au Gabon: un atout pour le bien être de la population. World health report, 2010.

28. McIntyre, D., et al., Promoting universal financial protection: evidence from seven low-and middleincome countries on factors facilitating or hindering progress. Health research policy and systems, 2013. 11(1): p. 36.

29. Mills, A., et al., Equity in financing and use of health care in Ghana, South Africa, and Tanzania: implications for paths to universal coverage. The Lancet, 2012. 380(9837): p. 126-133.

30. Fusheini, A., The politico-economic challenges of Ghana's national health insurance scheme implementation. International journal of health policy and management, 2016. 5(9): p. 543. 